\section{Leaf Chlorosis and Seed Yield of Dry Beans Grown on High-pH Calcareous Soil following Foliar Iron Sprays}

\author{
H.Z. Zaiter ${ }^{1}$ and D.P. Coyne ${ }^{2}$ \\ Department of Horticulture, University of Nebraska, Lincoln, \\ NE 68583-0724
}

\author{
R.B. Clark ${ }^{3}$ \\ U.S. Department of Agriculture, Agricultural Research Service, \\ Department of Agronomy, University of Nebraska, Lincoln, \\ NE 68583-0817
}

\section{D.T. Lindgren ${ }^{4}$ and P.T. Nordquist ${ }^{5}$ \\ West Central Research and I\&tension Center, North Platte, NE 69101}

W.W. Stroup ${ }^{6}$ and L.A. Pavlish ${ }^{7}$

Department of Biometry, University of Nebraska, Lincoln, NE 68583-0712

\author{
Additional index words. Phaseolus vulgaris, genotypic variation, iron-deficiency \\ chlorosis
}

Abstract. Iron deficiency chlorosis (FeDC) causes extensive reduction in yields of edible dry beans (Phaseolus vulgaris L.) grown on high-pH and calcareous soils. Fifteen bean cultivars/lines differing in response to FeDC were grown 2 years (1988 and 1989) on a high-pH (8.0), calcareous $(2.3 \%$ calcium carbonate equivalent in surface $20 \mathrm{~cm})$, and low-Fe (2.2 mg Fe/kg) Typic Haplustolls silt loam in the field (central Nebraska) to determine the effects of FeDC on seed yield of cultivars/lines sprayed with Fe. A significant interaction $(P<0.05)$ between cultivars/lines $\times$ Fe spray treatment was noted for visual FeDC ratings in 1988 only, and no significant interactions were noted for seed yield either year. Sprayed cultivars/lines generally produced higher yields than unsprayed ones. Overall increases were $47 \%$ in 1988 and $41 \%$ in 1989 . Even though only slight FeDC was noted on some cultivars/lines receiving no Fe spray, seed yields were significantly increased when sprayed with $\mathrm{Fe}$. Some cultivars/lines with moderate or moderately severe FeDC ratings did not show a significant increase in yield when sprayed with Fe, while other cultivars/lines did. Seed yield reductions for the cultivars/

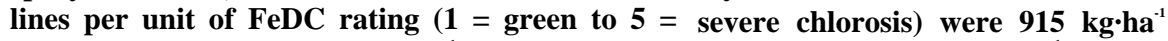
for unsprayed and $1518 \mathrm{~kg} \cdot \mathrm{ha}^{-1}$ for sprayed plants in 1988 and $344 \mathrm{~kg} \cdot \mathrm{ha}^{-1}$ for unsprayed and $608 \mathrm{~kg} \cdot \mathrm{ha}^{-1}$ for sprayed plants in 1989.

Iron deficiency chlorosis (FeDC) is a major constraint for production of many crops,

Received for publication 30 Dec. 1991. Accepted for publication 3 Apr. 1992. Published as Paper no. 9763, Journal Series, Nebraska Agricultural Research-Division. Research was conducted under Title XII Bean/Cowpea CRSP Project at Univ. of Nebraska under USAID Contract no. DAN-1310G-SS-6008-00 and under Project nos. 20-036 and 20-042. Mention of trade name, proprietary product, or vendor does not constitute an endorsement or warranty by the Univ. of Nebraska or the U.S. Dept. of Agr., nor does it imply its approval to the exclusion of other products or vendors that may be suitable. The cost of publishing this paper was defrayed in part by the payment of page charges. Under postal regulations, this paper therefore must be hereby marked advertisement solely to indicate this fact.

${ }^{1}$ Research Associate. Present address: Assistant Professor and Head, Crop Production and Protection Dept., American Univ. of Beirut, Republic of Lebanon.

George Holmes Professor.

Research Plant Physiologist.

${ }^{4}$ Associate Professor of Horticulture.

Professor of Agronomy.

Associate Professor.

Statistical Specialist. such as edible dry beans, when grown on high-pH calcareous soils of the Great Plains (Clark, 1982; Coyne et al., 1973). Seed yield losses in bean cultivars/lines would likely occur due to this disorder, but these have not been documented.

Soybean [Glycine $\max (\mathrm{L}$.$) Merr.] and$ sorghum [Sorghum bicolor (L.) Moench] are sensitive to FeDC when grown on calcareous soils. Soybean seed yields decreased by $20 \%$ per unit of visual leaf FeDC rating $(1=$ no chlorosis to $5=$ severe chlorosis) (Froehlich and Fehr, 1981) and by 740 to $940 \mathrm{~kg} \cdot \mathrm{ha}^{-1}$ per unit of visual leaf FeDC rating $(1=$ no chlorosis to $5=$ severe chlorosis and $6=$ dead plants) (Kinkaid, 1986). Grain yield losses of sorghum varied with year, site, source and timing of foliar spray or soil amendment, and genotype (Clark et al., 1990). Yield losses occurred when visual leaf FeDC ratings in sorghum were between slight and moderate (Clark et al., 1988; Williams et al., 1986). Predicted yield losses were 1090 $\mathrm{kg} \cdot \mathrm{ha}^{-1}$ per unit of visual FeDC rating (Clark et al., 1988).

The objectives of our study were to determine: 1) yield losses due to Fe deficiency as expressed by visual leaf FeDC symptoms in edible dry bean cultivars/lines grown on a high-pH calcareous soil and 2) the effects of Fe spray on cultivar/line seed yields grown on the same soil.

Fifteen bean cultivars/lines (Table 1) with different responses to FeDC (Zaiter et al., 1987; H.Z. Zaiter and D.P. Coyne, 198487 , personal observations) were grown 2 years (1988 and 1989) on a high-pH calcareous Cozad silt loam (saline and alkaline) soil (silty, mixed, mesic Typic Haplustolls) located near North Platte in central Nebraska. No fertilizer was applied to the plots in either year. The chemical properties of the soil were: $\mathrm{pH}$ 8.0 (1 soil : 1 water); $1.9 \%$ organic matter; $2.2 \%$ calcium carbonate equivalent in surface $20 \mathrm{~cm}$; $35.2 \mathrm{Ca}, 5.7 \mathrm{Mg}, 3.5 \mathrm{~K}$, and $0.86 \mathrm{Na}$ in $\operatorname{cmol}(+)$ grams soil; $1.4 \mathrm{dS} \cdot \mathrm{m}^{-1}$ electrical conductivity; and 222 nitrate, 32.6 $\mathrm{P}$ (extracted with $0.50 \mathrm{M}$ sodium bicarbonate, $\mathrm{pH} 8.5$ ), 5.0 Mn, 2.2 ammonium, 2.2 $\mathrm{Fe}, 1.1 \mathrm{Zn}$, and $0.22 \mathrm{Cu}[\mathrm{Mn}, \mathrm{Fe}, \mathrm{Zn}$, and $\mathrm{Cu}$ were extracted with $0.005 \mathrm{~m}$ diethylenetriaminepentaacetate (DTPA)] in milligrams per kilogram of soil.

Seeds of each cultivar were planted on 27 May 1988 and 24 May 1989 in 3-m-long single rows, $0.6 \mathrm{~m}$ between rows, and three to four plants per $0.3 \mathrm{~m}$ of row. The experiment was conducted as a split-plot. The whole-plot treatments were Fe sprayed and not sprayed, arranged in randomized complete blocks (six replications in 1988 and four in 1989). The split-plot treatments were cultivars/lines. Plots were sprayed to runoff with a hand-held sprayer three times each year (29 June, 14 July, and 1 Aug. in 1988 and 29 June, 18 July, and 15 Aug. in 1989) with Fe at $0.5 \mathrm{~kg} \cdot \mathrm{ha}^{-1}$ as FeEDDHA [ferric ethylenediiminobis(2-hydroxyphenyl)-acetate, "Sequestrene-138 Fe"; CIBA-Geigy, Greensboro, N.C.] with Tween-80 added as a surfactant. Trifluralin [2,6-dinitro- $N, N$-dipropyl-4-(trifluoromethyl)benzenamine] at 1.2 liters-ha-' was soil-incorporated before planting each year for weed control. Plots were furrow-irrigated about every 10 days throughout the growing season.

Visual leaf FeDC ratings were rated each year, before the first (second trifoliate leaves fully expanded) and second (flowering and late vegetative stage) $\mathrm{Fe}$ spray treatments were applied. On a scale where $1=$ normal green leaves, $2=$ trace of FeDC symptoms on an occasional leaf, 3 = moderate FeDC symptoms on several leaves, $4=$ moderately severe FeDC symptoms on most leaves, and 5 $=$ severe FeDC symptoms on all leaves. The FeDC scores each year were combined to give one mean for the cultivars/lines per treatment each year since the FeDC ratings appeared similar. Seed yields (13\% moisture) were determined after harvest.

Data were tested using a split-plot analysis of variance (Milliken and Johnson, 1984). Calculations were performed using the SASGeneral Linear Model procedures as the calculating tool (SAS Institute, 1991).

A significant interaction $(P<0.05)$ between cultivars/lines and Fe spray treatment was noted for visual FeDC ratings in 1988 only, and no significant interactions for these 
treatments were noted for seed yield either year. All unsprayed cultivars/lines showed some FeDC symptoms on leaves each year (Table 1). Some cultivars/lines had more severe FeDC symptoms than others. The least chlorotic in the unsprayed plots each year were WM1-83-10, 'Ul-111', 'Valley', and 'Spinel'. Those with the most severe FeDC symptoms within years were 'Steuben Yellow Eye', 'Pilgram', 'Redkloud', 'Tuscola', and PI 165078. All unsprayed cultivars/lines had higher FeDC ratings than the sprayed cultivars/lines in 1988, but in 1989, only seven of the 15 cultivars/lines had higher FeDC ratings than those in the sprayed plots.

All cultivars/lines, except 'Redkloud', 'Steuben Yellow Eye', and 'Pilgram' in 1988 and 1989 and 'Fleetwood', 'White Kidney', and PI 165078 in 1989, responded to the Fe sprays both years with significant increases in seed yields (Table 1). Considerable cultivar/line variability for yield was noted. WM1-83-10 and 'Valley' had high seed yields both years whether they were sprayed or not, while 'Redkloud', 'Steuben Yellow Eye', and 'Pilgram' had low yields under both treatments. The Fe spray did not significantly increase seed yields of these latter cultivars/ lines with moderate to moderately severe FeDC ratings. 'Tuscola' (moderately severe and moderate FeDC ratings in 1988 and 1989, respectively) responded to the $\mathrm{Fe}$ spray treatment with significant increases in yield both years. PI 165078 (moderately severe FeDC ratings both years) only showed significant yield increases with the Fe spray treatment in 1989.

Seed yields below $\approx 2000 \mathrm{~kg} \cdot \mathrm{ha}^{-1}$ are considered below an economic level for drybean production on farms in western $\mathrm{Ne}$ braska based on prices in recent years (D.T. Lindgren and D.S. Nuland, personal communication). Commercial bean fields are not sprayed with $\mathrm{Fe}$ in Nebraska. Several unsprayed cultivars/lines, particularly WMl-8310 and 'Valley', produced yields in 1988 above an economic level even though they showed some visual leaf FeDC symptoms (Table 1). The yields of these two entries, along with all other entries, were below an economic level in unsprayed plots and were above that level in the sprayed plots in 1989. 'Redkloud', 'Steuben Yellow Eye', Tuscola, PI 165078, and 'Pilgram', severely susceptible when not sprayed, produced yields below an economic level even when sprayed with Fe in 1988. WM1-83-10 and 'Valley' could be considered more resistant to FeDC than many of the cultivars/lines.

Overall seed yield increases of all cultivars/lines due to $\mathrm{Fe}$ sprays were $47 \%$ in 1988 and $41 \%$ in 1989 . We partly attribute the lower yields in 1989, in comparison to 1988 , to a period of $5 \mathrm{C}$ higher day and night temperatures during the period of bloom of the entries (K. Hubbard, personal communication). The higher temperatures may have caused more blossom drop and reduced pod set. Many of the cultivars/lines sensitive to FeDC yielded relatively well when grown under favorable conditions in western $\mathrm{Ne}$ braska (D.S. Nuland and C. Carlson, 1988;
Table 1. Visual leaf FeDC ratings and seed yields (estimated uncertainty $\pm 5 \mathrm{~kg}$ ) of dry bean cultivars/ lines grown on high-pH calcareous soil.

\begin{tabular}{|c|c|c|c|c|c|c|c|c|c|}
\hline \multirow[b]{3}{*}{ No. ${ }^{y}$} & \multirow[b]{3}{*}{ Cultivar/line } & \multicolumn{4}{|c|}{ FeDC (chlorosis) rating ${ }^{2}$} & \multicolumn{4}{|c|}{ Seed yield $\left(\mathrm{kg} \cdot \mathrm{ha}^{-1}\right)$} \\
\hline & & \multicolumn{2}{|c|}{1988} & \multicolumn{2}{|c|}{1989} & \multicolumn{2}{|c|}{1988} & \multicolumn{2}{|c|}{1989} \\
\hline & & & & $\mathrm{US}^{\mathrm{x}} \mathrm{S}$ & US & US & $\mathrm{S}$ & US & $S$ \\
\hline 1 & WMI-83-10 & 2.2 & 1.4 & 1.1 & 1.0 & 2656 & 3607 & 1531 & 2233 \\
\hline 2 & Valley & 2.2 & 1.2 & 2.2 & 1.1 & 2596 & 3470 & 1496 & 2422 \\
\hline 3 & Harris & 2.5 & 1.5 & 3.0 & 2.2 & 2447 & 2877 & 1353 & 1816 \\
\hline 4 & UI-59 & 3.4 & 1.9 & 3.2 & 1.7 & 2175 & 2648 & 1323 & 1743 \\
\hline 5 & JM-24 & 2.7 & 1.6 & 2.3 & 1.2 & 2036 & 3438 & 1444 & 1912 \\
\hline 6 & Spinel & 2.3 & 1.0 & 2.0 & 1.2 & 1794 & 2610 & 1016 & 1868 \\
\hline 7 & UI-111 & 2.6 & 1.7 & 1.4 & 1.1 & 1790 & 2467 & 1280 & 1742 \\
\hline 8 & Fleetwood & 2.6 & 1.2 & 2.6 & 1.2 & 1741 & 2559 & 1741 & 1661 \\
\hline 9 & Beryl & 3.2 & 2.0 & 2.3 & 1.4 & 1706 & 2416 & 1431 & 1934 \\
\hline 10 & White Kidney & 2.8 & 1.5 & 4.2 & 3.5 & 1658 & 2252 & 1207 & 1552 \\
\hline 11 & PI 165078 & 3.9 & 1.6 & 3.8 & 2.6 & 595 & 1264 & 447 & 662 \\
\hline 12 & Tuscola & 4.1 & 2.3 & 3.2 & 2.2 & 334 & 1242 & 460 & 910 \\
\hline 13 & Pilgram & 4.6 & 2.2 & 4.5 & 3.4 & 311 & 635 & 248 & 376 \\
\hline 14 & Steuben Yellow Eye & 4.9 & 3.1 & 3.0 & 2.4 & 293 & 491 & 312 & 398 \\
\hline \multirow[t]{2}{*}{15} & Redkloud & 4.2 & 2.4 & 4.0 & 2.8 & 38 & 541 & 224 & 460 \\
\hline & $\operatorname{LSD}(0.05)^{\mathrm{w}}$ & $1=0.6$ & $2=0.6$ & $1=0.8$ & $2=0.8$ & $1=538$ & $2=538$ & $1=438$ & $2=424$ \\
\hline
\end{tabular}

${ }^{2} \mathrm{FeDC}$ (chlorosis) ratings were $1=$ normal green leaves, $2=$ trace of FeDC symptoms on an occasional leaf, 3 = moderate FeDC symptoms on several leaves, 4 = moderately severe FeDC symptoms on most leaves, and $5=$ severe FeDC symptoms on all leaves.

'Seed classes were: 1 = black seed; $2,3,4,5,6,9=$ great northern; 7 = pinto; $8,12=$ navy: $10=$ commercial white kidney, cultivar not known; 11 = large flat white: 13 = large-seeded round white; $14=$ large-seeded white (eye pattern); and $15=$ light red kidney.

${ }^{x} \mathrm{US}=$ unsprayed and $\mathrm{S}=$ sprayed with FeEDDHA.

"LSD-1 = comparison of cultivars/lines means within each Fe spray treatment, and LSD-2 = comparison of Fe spray treatment means within or between cultivars/lines.
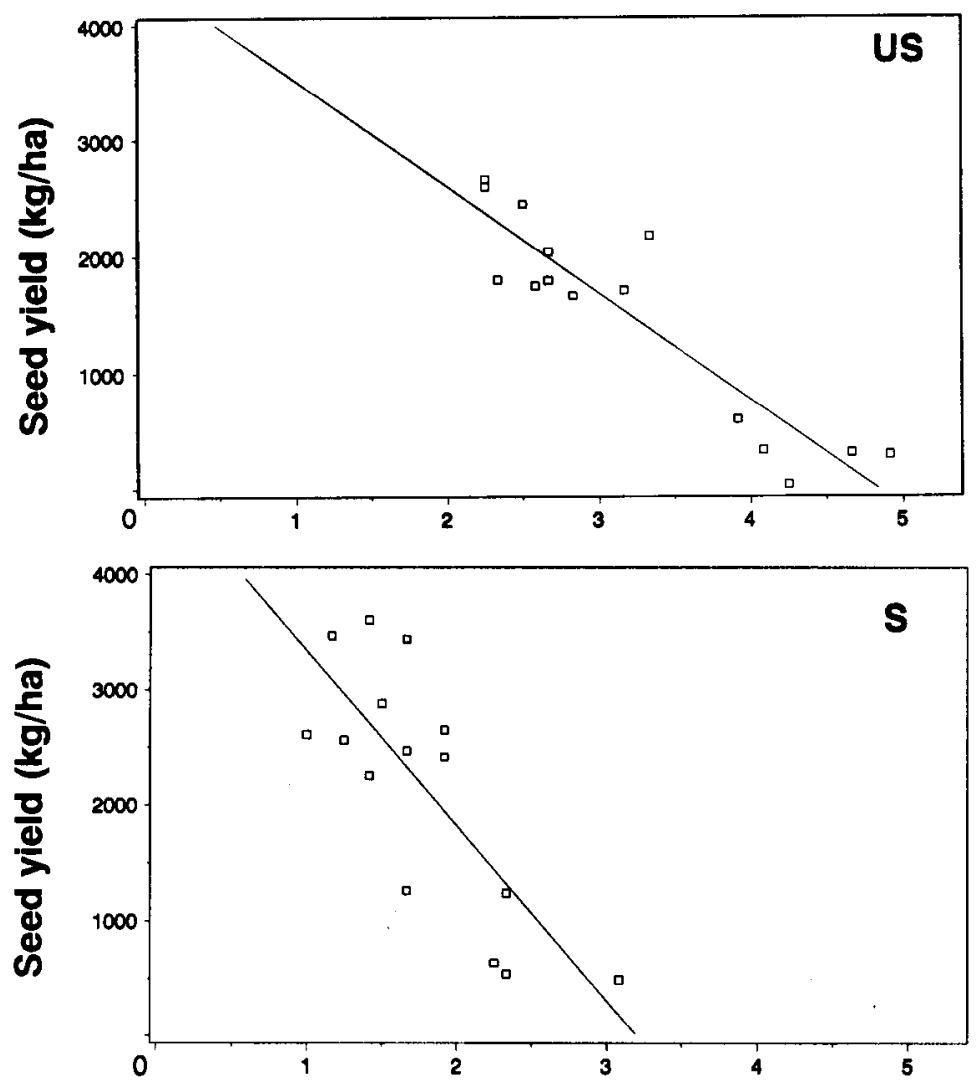

FeDC rating

Fig. 1. Linear regressions of seed yield on visual leaf FeDC ratings $(1=$ normal green leaves, $2=$ trace of FeDC symptoms on an occasional leaf, $3=$ moderate FeDC symptoms on several leaves, $4=$ moderately severe FeDC symptoms on most leaves, and $5=$ severe FeDC symptoms on all leaves) of unsprayed (US) and sprayed (S) dry bean cultivars/lines grown on high $\mathrm{pH}$ calcareous soil in 1988. Linear regression equations and $R^{2}$ values were: $9=4431-915 \mathrm{x}$ with $R^{2}=0.83$ for unsprayed; and $\mathrm{y}=4858-1518 \mathrm{x}$ with $R^{2}=0.60$ for sprayed cultivars/lines. 

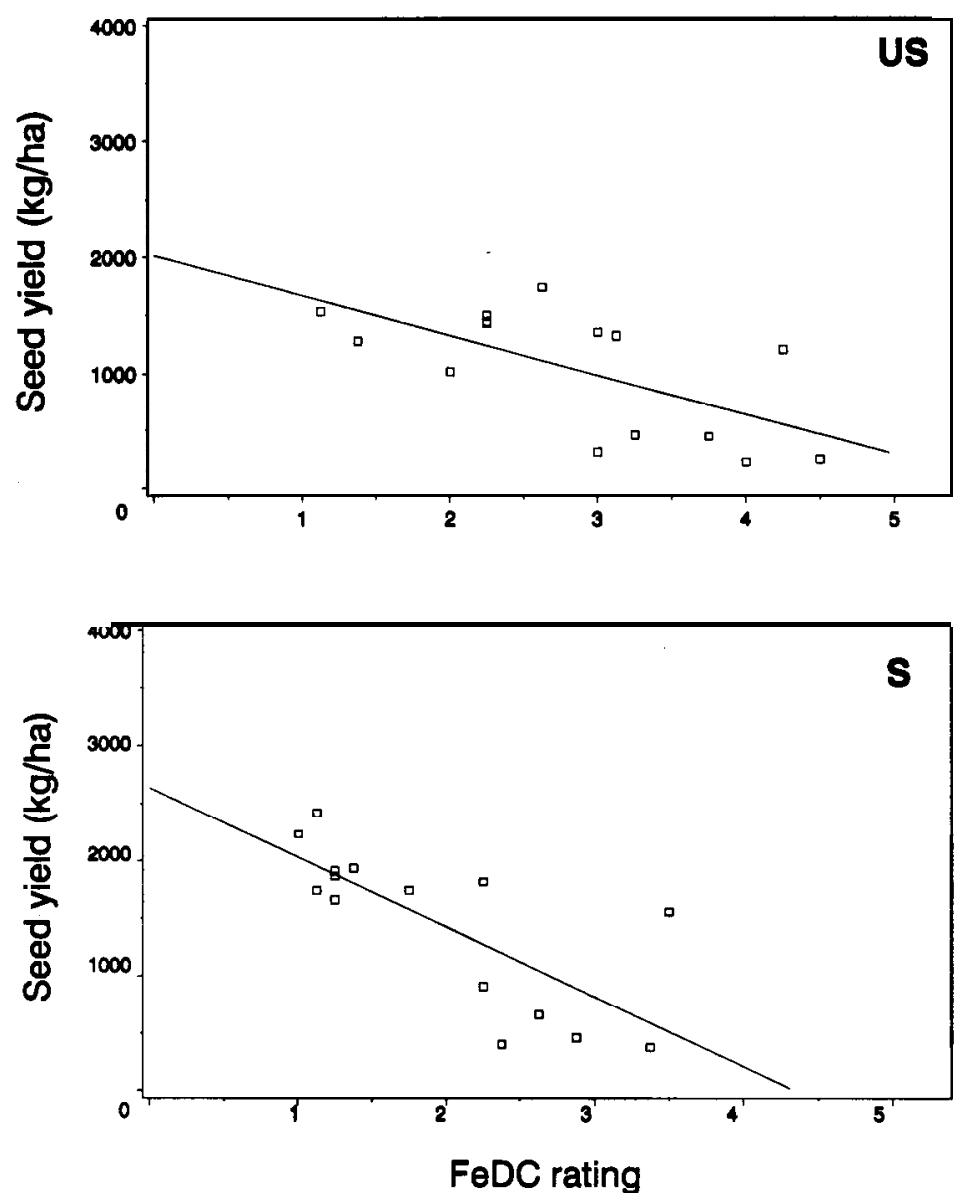

Fig. 2. Linear regressions of seed yield on visual leaf FeDC ratings $(1=$ normal green leaves, $2=$ trace of FeDC symptoms on an occasional leaf, $3=$ moderate FeDC symptoms on several leaves, $4=$ moderately severe FeDC symptoms on most leaves, and $5=$ severe FeDC symptoms on all leaves) of unsprayed (US) and sprayed (S) dry bean cultivars/lines grown on high-pH calcareous soil in 1989. Linear regression equations and $R^{2}$ values were: $9=2015-344 \mathrm{x}$ with $R^{2}=0.41$ for unsprayed; and $\mathrm{y}=2637-608 \mathrm{x}$ with $R^{2}=0.56$ for sprayed cultivars/lines.

D.P. Coyne and D.S. Nuland, 1983-89, unpublished data). Even though these sensitive cultivars/lines responded to the Fe spray with reduced visual leaf FeDC symptoms, they still did not produce economic seed yields, perhaps because the soils used in this study induced such severe abiotic stresses on these unadapted cultivars/lines that they could not be alleviated, even with Fe sprays.

Seed yield and visual leaf FeDC ratings were negatively related (Figs. 1 and 2). Decreases in seed yield per unit of visual leaf
FeDC rating were $915 \mathrm{~kg} \cdot \mathrm{ha}^{-1}$ in 1988 and $344 \mathrm{~kg} \cdot \mathrm{ha}^{-1}$ in 1989 for unsprayed cultivars/ lines and $1518 \mathrm{~kg} \cdot \mathrm{ha}^{-1}$ in 1988 and 608 $\mathrm{kg} \cdot \mathrm{ha}^{-1}$ in 1989 for sprayed cultivars/lines. Decreases in seed yield were larger for sprayed than for unsprayed cultivars/lines per unit of visual leaf FeDC rating. The decreases in seed yield most likely were larger for sprayed compared to unsprayed cultivars/lines because Fe-sprayed plants had higher yields than unsprayed plants and ranges of visual leaf FeDC ratings for sprayed plants were nar- rower than for unsprayed plants.

These results clearly indicate that considerable losses in seed yield of edible dry bean cultivars/lines can occur when plants are grown on high-pH calcareous soils that induce visual FeDC symptoms on leaves. Spraying with $\mathrm{Fe}$ could produce improved economic seed yields in some cultivars/lines when grown on these kind of soils. Additional field trials should be conducted under slightly less severe soil conditions to determine the value of Fe sprays on these cultivars/lines.

\section{Literature Cited}

Clark, R.B. 1982. Iron deficiency in plants grown in the Great Plains of the U.S. J. Plant Nutr. 5:351-268.

Clark, R.B., D.P. Coyne, W.M. Ross, and B.E. Johnson. 1990. Genetic aspects of plant resistance to iron deficiency, p. 1096-1115. In: S.K. Sinha, P.V. Sane, S.C. Bhargava, and P.K. Agrawal (eds.). Proc. Congr. Plant Physiol., vol. 2, 1st Intl. Soc. Plant Physiol. Biochem., Water Tech Centre, Indian Agr. Res. Inst., New Delhi, India.

Clark, R.B., E.P. Williams, W.M. Ross, G.M. Herron. and M.D. Witt. 1988. Effect of iron deficiency chlorosis on growth and yield component traits of sorghum. J. Plant Nutr. 11:747754.

Coyne, D.P., F.N. Anderson, C.L. Ashburn, C.R. Fenster, A.F. Hagen, O.W. Howe, D.W. Lancaster, M.L. Schuster, and J.R. Steadman. 1973. Growing dry edible beans in Nebraska. Univ. of Nebraska (Lincoln) Agr. Expt. Sta. Bul. 527.

Froehlich, D.M. and W.R. Fehr. 1981. Agronomic performance of soybeans with differing levels of iron deficiency chlorosis on calcareous soil. Crop Sci. 21:438-441.

Kinkaid, B.D. 1986. Varietal and soil effects on lime-induced chlorosis of soybeans [Glycine max (L.) Merr.]. MS Thesis, Univ. of Nebraska, Lincoln.

Milliken, G.A. and D.E. Johnson. 1984. Analysis of messy data, vol. 1: Designed experiments. Van Nostrand Reinholt, New York.

SAS Institute. 1991. SAS users guide: Statistics. version 6 (ed.). SAS Institute Inc., Cary, N.C.

Williams, E.P., W.M. Ross, R.B. Clark, G.M. Herron, and M.D. Witt. 1986. Iron deficiency chlorosis: Its heritability and effects of agronomic traits in a sorghum population. J. Plant Nutr. 9:423-433.

Zaiter, H.Z., D.P. Coyne, and R.B. Clark. 1987. Genetic variation and inheritance of resistance of leaf iron-deficiency chlorosis in dry beans. J. Amer. Soc. Hort. Sci. 112:1019-1022. 